\title{
CONSIDERAÇÕES GERAIS SOBRE A DÉCADA DA INDEPENDÊNCIA E A EDUCAÇÃO ATRAVÉS DE SUA LEGISLAÇÃO ESPECIFICA (*).
}

\author{
JOSEFINA CHAIA PEREIRA \\ da Faculdade de Filosofia, Ciências e Letras de \\ Marília (SP):
}

Duzentas e dezenove determinações legais na década focada foram fixadas para os diferentes graus e ramos do ensino, atividades e instituições que deram impulso à Educação. Destacam-se, entre outras:

- criação provisória do Curso Jurídico na Corte,

- permissão dos oficiais do exército para estudar na Europa,

- José da Silva Lisboa é encarrgeado de escrever a História dos Sucessos do Brasil, desde o dia 26 de fevereiro de 1821,

- abertura da Academia de Belas Artes. Criação de inúmeros cursos, entre outros:

- cursos Jurídicos de São Paulo e Olinda,

- do Observatório Astronômico,

- do Gabinete Inglês de Leitura,

- restabelecimento do Seminário de São Joaquim,

- isenção de recrutamento dos alunos que "deram provas e esperanças" de aplicảção nos estudos,

- criação de escolas de primeiras letras em todas as vilas e lugares populosos do Império,

- adoção do método Lancasteriano,

- iniciação das aulas de Pintura, Desenho, Escultura e Giravura, na Corte,

- auxílio aos alunos pobres da Academia Médico Cirúrgica,

- criação do ofício de Interprete de Língua Inglesa,

- despacho livre de direito de importação às obras literárias,

- criação do cargo de Inspetor Geral dos Estabelecimentos Literários e Científicos,

(*). - Comunicação apresentada na 3.a Sessão de Estudos, no dia 7 de julho de 1972 (Nota da Redação). 
- concessão de aposentadoria a professor público,

- exigência do atestado de frequência para os professores receberem os vencimentos,

- licença para a abertura de um Curso de Medicina Prática,

- criação de uma comissão para organizar um projeto de regimento para as escolas de primeiras letras,

- criação de uma comissão para Estatística Geográfica e Natural, Política e Civil,

- obrigatoriedade do atestado de estudos nos exames de preparatórios,

- regulamentação da cobrança de subsídio literário, e da mais alta importância, a Constituição de 25-3-1824 que no Título 8, Art. 179 item XXXIII, ocupa-se da Educação.

Procuraremos abordar apenas um aspecto das duas centenas das Leis, Decretos, Decisões e Portarias, pois seria bastante longo um comentário a respeito de sua totalidade. Nosso enfoque porá em relevo apenas a "exposição de motivos" ou justificativas das mais importantes.

Através das razões avocadas e que levaram à Lei poderemos tei: uma visão certamente parcial, mas não menos significativa para o conhecimentơ da situação do Brasil entre 1820 e 1829.

A primeira Carta Régia do período sobre o tema, data de 12-11820, em que El-Rei comunica ao Governador e Capitão Geral da Capitania de São Paulo, João Carlos Augusto de Oeynhausen, que atende ao pedido do Bispo da Diocese sobre a necessidade da criação de uma cadeira de História Eclesiástica,

$$
\begin{aligned}
& \text { "para a instrução de seu clero, e a falta de meios que ele } \\
& \text { tem ..." }
\end{aligned}
$$

e nomeia o Presbítero Secular, para professor, o senhor Manoel Joaquim do Amaral Gurgel, com o ordenado de 150\$000. é de

Considerando que um plano bem formado de estudos menores

\footnotetext{
"grande utilidade para a vida litteraria, e usos da civilização e porque os seus principios são necessários aos que se dedicam às Faculdades em que não fazem parte de seus estudos"
} 
são criadas 8 aulas de primeiras letras e 6 aulas elementares na Capitania de São Pedro em atendimento à proposta do Governador e Capitão Geral da Capitania (1).

Os Moradores do Arraial de Sant'Anna de Angelical e Julgado de Campo Largo, da Comarca do Sertão de Pernambuco, represenlam sobre

"a impossibilidade que têm de fazer a conveniente instrução à mocidade, por não haver ali, nem na distância de 50 lśguas uma escola, em que possa aprender ao menos a ler, escrever e contar"

e conseguem a criação de una cadeira de primeiras letras no Arraial de Sant'Anna de Angelical (2). queza ...."

“. . achando-se em grande augmento de populaçãu e ri-

a. Vila de Parnaíba, da Província do Piauí, consegue restaurar (sic) a cadeira de Gramática Latina, pelo Decreto de 4-3-1820.

"Por ser indispensavei para a educação e instrução da mocidade dos colonos suissos ...."

é criada uma cadeira de primeiras letras e outra de Gramática Latina e Portuguesa na Vila de Nova Friburgo, da Província do Rio de Janeiro, sendo indicado para professor das mesmas Antônio José de Paiva Guedes de Andrade (3).

A Mesa do Desembargo do Paço foi ouvida sobre o requerimento de Carlos Mathias Pereira, expondo a necessidade de haver na Corte um tradutor de línguas estrangeiras. Teve o seguinte parecer do Desembargador Juiz da Alfândega:

"Tendo crescido o commercio estrangeiro neste Porto $\mathrm{cnm}$ a abertura e franqueza de todos os deste Reino, são freculuentes as occasiōes de um interprete de línguas estrangeiras autorizado pelo público para as traduções dos muitos documentos qụe se apresentam no commercio, e ainda na Alfandega, não sendo bas-

(1). - Resolução $n^{\circ}$ 3, de Consulta da Mesa do Desembargo do Paço de $14 / 1 / 1820$.

(2). - Decreto de $17 / 1 / 1820$.

(3). - Decreto de $3 / 6 / 1820$. 
tante o que existe das línguas inglêsa e franceza. Que o supplicante, além destas línguas, sabe bem o allemão, hollandez, dinamarquez, e sueco; e parece razoavel a taxa que pede, de $1 \$ 200$ por folha de duas paginas, que é a metade do que se percebe nos consulados ..."

foi o primeiro intérprete de línguas estrangeiras nomeado, em 17-71820 .

"Escripta" no Palácio do Rio de Janeiro, em 14-9-1820, é destinada a Luiz do Rego Barreto, Governador e Capitão Geral da Capitania de Pernambuco, a Carta Régia aprova na Vila do Recife, em Pernambuco,

“. . . importante estabelecimento de um collegio de educação para nelle instruir a mocidade, , provendo-o de bons mestres de primeiras lettras, das linguas ingleza, e franceza, de arithmetica, geometria, desenho civil e militar..."

O aumento da população da Freguesia de São Boaventura de Canavieiras da Comarca de Ilhéus, e Capitania de Pernambuco,

“. . e as difficuldades que tem os pais de familias que nella residem, de fazerem instruir seus filhos mandando-os à Villa dos Ilheos que della dista mais de 22 léguas por caminhos àrduos e perigosos pelas passagens de barras dos rios que cortam aquella comarca ..."

é criada uma escola de primeiras letras (4).

A Decisão n.o 57 - Reino, de 18-10-1820 determina que se dê despacho livre de direitos de importação às obras literárias que vierem de países estrangeiros, e a Decisão n.o 24 - Reino de 8-51821 permite às alfândegas o despacho livre de obras literárias de qualquer natureza,

“. . . não sendo obcenos. . .."

"Tendo em consideração a que' as artes do desenho, pintura, e escultura e architectura civil, são indispensáveis à civilização dos povos e instrucção publica dos meus vassallos, alem do augmento e perfeição que podem dar aos objectos da industria, p!ısica, e historia natural ..."

(4). - Decreto de 17/10/1820. 
é criada a Academia de Derenho, Escultura e Arquitetura Cicil, pelo Decreto de 23-11-1820. Com a mesma dáta, outro Decreto manda principiar, com o nome de Academia das Artes, as aulas de pintura, desenho, escultura e gravura, estabelecidas na Corte pelo Decreto de 12-8-1816, enquanto não se pudesse organizar uma Escola Real de Ciências, Artes e Ofícios.

\section{A Augusta Presença de El-Rei Nosso Senhor atendendo ao}

"quanto é necessário esta arte (aula de desenho) a todos os trabalhos mecanicos..."

manda admitir na aula de desenho do Arsenal do Exército, as pessoas que de seu estudo quiserem aproveitar (5).

“. . . e com o fim de habilitar pessoas que possam depois serem convenientemente empregadas como cirurgiōes nas minhas tropas e nas diversas províncias deste Reino, onde haja ialta de Professor de Saude..."

Com a justificativa acima, e com a rubrica de El-Rei Nosso Senhor, o Decreto de 16-12-1820 estabelece 12 pensões mensais para a subsistência de 12 alunos pobres da Academia Médico-Cirúrgica da Corte.

A partir de 23-4-1821, a Regência do Reino, em nome de ElRei o Senhor D. João VI faz saber que

"As Cortes Geraes Estraordinarias e Constituintes da Nação Portugueza, convencidas de que o uzo das tenções em latin, pratịcado nas Relaçốes deste Reino, somente servem para demorar a prompta administração da Justiça, que com maior facilidade e exactidão se pode explicar na lingua Portuguza, decretam:"

a abolição do estilo das tensões em latim, devendo as mesmas serem escritas na língua Portuguesa.

Dois foram os motivos que levaram as Cortes Gerais Extraordinárias e Constituintes da Nação Portuguesa, permitir a qualquer cidadão o ensino e a abertura de escolas de primeiras letras, independente de exame ou licença:

(5). - Decisão n 54 - Guerra, em 11/12/1820. 
"Attendendo a que não é possivel desde já estabelecer, com como convem, Escolas em todos os logares deste Reino por conta da Fazenda Publica; e Querendo assegurar a liberdade que todo o Cidadão tem de fazer o devido uso de seus talentos. nȧo se seguindo dahi prejuizoz publicos . . . . Decreto de 30/6/1821.

O Príncipe Regente, desejando promover

“. . . quanto é possível, a instrucção publica pelos grandes beneficios que della resultam à Igreja e ao Estado",

cria cadeiras de Retórica e de Filosofia na Vila de Paracatu do Príncipe da Capitania de Minas Gerais, porque

“. . . sem embargo de sere mos sertões daquella Comarca e de todas as outras proximas ao Rio de São Francisco do Norte, muito populosos e abundantes de viveres necessarios a manter os principaes necessidades da vida, a falta do numerario privit os seus habitantes de frequentarem aquelles estudos fora de sua Patria, pela grande distancia das terras onde se acham estabelecidas as competentes aulas..." (6)

O Príncipe Regente justifica o Decreto de 19-5-1821:

"... mui conforme aos desejos que tenho de promover e auxiliar quanto for possivel, a educação da mocidade, princinalmente da classe daquelles que privados pela sua orphandade lhes faltam os meios da adquirirem a instrucção precisa para que rhegados a maioridade possam ser uteis a sí, à Igreja e ao Esłado, cuja prosperidade em grande parte depende da moral, costumes e instrucção publica e particular de cada um de seus membros ..."

:estabelece o Seminário de São Joaquim, determina a formação de uma Junta de Síndicos, e nomeia Reitor.

"Desejando S. M. o Imperador promover a Instrucção l’ublica, e lembrando-se que no Arsenal do Exercito se pode estabelecer uma Escola de Primeiras Letras, onde os operários das diversas officinas, com facilidade e commodo poderão obter aquella previa instrucção..."

(6). - Decreto de 17/5/1821. 
Inanda através da Secretaria dos Negócios da Guerra, participar à Junta da Fazenda dos Arsenais do Exército, Fábricas e Fundições, que encarregou o Major José dos Santos e Oliveira, o estabelecimento de uma Escola de Primeiras Letras dentro do Arsenal, para os operários (7).

"Convindo promover a instrucção de uma classe tão distincta dos meus subditos, qual a da corporação militar, e achando-se geralmente recebido o methodo do Ensino Mutuo, pel ațacilidade e precisão com que se desenvolve o espirito, e o prepara para a aquisição de novas e mais transcendentes ideas..."

é criada na Corte uma Escola de Primeiras Letras, na qual se ensinará pelo Método Lancasteriano,

". . . sendo em beneficio, não somente dos militares do Exercito, mas de todas as classes dos meus subditos que queiram aproveitar-se de tão vantajoso estabelecimento" (8).

O Decreto de 9 de janeiro de 1825 , cria provisoriamente um Curso Jurídico na Corte, com a Justificativa:

"Querendo que os habitantes deste vasto e rico Imperio, gozem, quanto antes, de todos os benefícios promettidos na Constituição, Art. $179 \S 33$ (9), e em considerando ser destes a edıcação publica e instruç̧ão, o conhecimento de Direito Natural, Publico, e das Gentes, e das Leis do Imperio, a fim de se poderem conseguir para o futuro magistrados habeis e intelligentes, sendo aliás da maior urgencia acautelar a notoria falta de Bachareis formados para os lugares da Magistratura pelo. Estado de Independencia Politica, a que se elevou este Imperio, que torna incompatível ir demandar, como d'antes, estes conhecimentos à Universidade de Coimbra, ou ainda a quaesquer outros paize; estrangeiros, sem grandes dispendios e incommodos, e não se podendo desde já obter os fructos desta indispensavel instrucção, se ella se fizer depende de grandes e dispendiosos estabelecimentos de Universidades, que ś́ com o andar do tempo poderão completamente realizar-se: Hei por bem, ouvido o Meu Co-selhs de Estado, crear provisoriamente um Curso Juridico nesta Côrte e

(7). - Decisão $n^{\circ} 143$ - Guerra, em 25/11/1822.

(8). - Decreto de $1 / 3 / 1823$.

(9). - "Colégios e universidades, onde se ensinarão os elementos das ciências, belas-letras e artes". 
cidade do Rio de Janeiro, com as convenientes Cadeiras, e I.en. tes, e com o Methodo, formalidade, regulamento e instrucções, que baixarão assignadas por Estevão $\mathbf{R}$.de Rezende, do Meu Conselho, Meu Ministro e Secretario de Estado e tenha assim entendido e o faça executar com os despachos necessários".

Em 29 de janeiro de 1825 é assinado o Decreto que manda oficiais do Exército estudar nas Escolas da Europa. O caput da determinação legal em foco, tem o seguinte teor:

“Attendendo a não ser bastante a força numerica, e disciplina ordinaria para levarem os exercitos aquelle grau de perfeição a que desejo elevar o deste Imperio, e não havendo por ora nelle todas as escolas, tanto theoricas, como praticas, que sño necessarias para que os Officiaes adquiram luzes sufficientes com que um dia, levando os soldados à victoria, consigam por ella a defeza do Imperio, e a sua propria gloria: Hei por bem que os Officiaes, declarados na relação, que com este baixa, vâo estudar nas escolas da Europa, na forma em tudo com as instrucções que tambem baixam assignadas, juntamente com a relaçĩo dos Officiaes, por João Vieira de Carvalho, do Meu Conse!ho, Ministro e Secretario de Estado dos Negocios de Guerra..."

Segue-se a relação dos treze oficiais agraciados. A seguir acompanha o Decreto as Instruções, estabelecidas em 6 artigos, cuja transcrição julgamos "oportuna.

"Convindo muito que os Officiaes do Exercito do Brasil possuam conhecimentos proprios de sua profissão, não se limitando aos das tres armas me particular, mas devendo abranger em geral a combinação das mesmas, atactica, estrategia e os differentes ramos de Artilharia, e Engenharia, ordenou Sua Magestade - Imperador, que fossem mandados alguns Officiaes à Europa, aonde se instruissem nas diferentes escolas militares, passando depois aos trabalhos praitcos de cada um dos ramos a que se tivesem aplicado, para que um dia paguem com seus conhecimentos a divida da sua educação.

Art. $1^{\circ}$ Os Officiaes nomeados terão a viagem paga até $\mathrm{Pa}$ riz, onde se apresentarão ao Agẹte dos Negocios do Brazil, Domingos Borges de Barros, ou a quem suas vezes fizer, o quil tudo fará por sua parte, para que preencham as vistas de Sua Magestade Imperial na adopção dos officiaes nas escolas militares, exercicios praticos, viagens, conferencias para discussões de pla- 
nos, bibliotecas, arsenaes, praças e mais estabelecimentos aonde possam beber doutrinas ou fixar idéas.

Art. $2^{9}$ Pelo conducto do Agente, receberão os officiaes a quantia liquida de $50 \$ 000$ mensaes, aquelles cujos vencimentos forem aqui menores; e os outros quantias iguaes às que aqui recebem, ficando o mesmo agente auctorisado a prestar proporcio nadas ajudas de custo, no caso de viagens, compras de liv os e instrumentos.

Art. $3^{\circ}$ Pelo intermedio do Age te dos Negocios em Pariz, memetterão os Officiaes todos os seis mezes, à Secretaria de Es. tado dos Negocios da Guerra, uma memoria escripta sôbre alg̣nns ramos que fizerem parte da sua applicação, a qual será acompanhada de um diario, quando se tenham ocupado em viasens ou ensaios, ou experiências sobre alguns dos ramos, com strtilharia, chimica, etc.

Art. 4\% Muito recommendaveis serão os Officiaes, se os diarios e memorias juntarem alguns planos 'e có tes de terrenos, edificios ou praças, assim como idéias geraes sobre po-tos de estatistica dos paizes que viajarem.

Art. $5^{\circ} \mathrm{A}$ regularidade de seus trabalhos, sua applicação e conducta, serão titulos de recommendação para os Officiaes: por elles será medido o tempo para sua volta (à custa do governo); - seu direito aos accessos lhe será guardado e mantido, e os premios ou os castigos coroarão sua fadigas ou castigarão seu desleixo.

Art. $6^{\circ}$ No caso de guerra européa (o que Deus não pernita) convirá a todos, ou alguns dos Officiaes, se una mcomo voluntários, para adquirirem melhores conhecimentos praticos, : 03 Exercitos daquella nação amiga do Imperio do Brazil e dos seus alliados, não somente mantiver a melhor disciplina, mas que mais sinceramente propugnar pela manutenção dos principios da Religiâo Catholica, e da realeza legitima".

$O$ Decreto de 3 de agosto de 1825 estende a oficiais baiano: a mesma oportunidade, isto é, a de estudar na Europa: o Alferes José B. Caldeira, do Batalhão da Artilharia, e os segundos tenentes Galdino Justiniano da Silva Pimentel, José Vicente de Amorim Bezerra, e o Cadete Joaquim Pessoa da Silva, do 7. ${ }^{\circ}$ Corpo de Artilharia de Posição de 1.a linha do Exército.

“. . por ser indispensavel o conhecimento delles para o acerto de muitas providencias, de que depende, em grarde parte, a prosperidade Geral da Nação ....." 
José F. F. Pinheiro, assina a Decisão no 110 - Império em 8-8-1826, que remete aos presidentes de província o plano para a organização dos trabalhos estatísticos e recomenda:

“... que neste importante trabalho se empreguem os individuos mais habeis da provincia..."

"Dom Pedro Primeiro, por Graça de Deus e Unanime aclamaçâo dos povos, Imperador Constitucional e Defensor Perpetuo do Brazil", faz saber a todos que a Assembleia Geral decretou e ele quer a seguinte Lei de 11 de agosto de 1827: Crea dnus Cursos de Sciencias Juridicas e Sociaes, um na cidade de S. Páulo e outro na de Olinda".

Anexado à Lei é transcrito o projeto de regulamento ou estatutos para o Curso Jurídico, organizado pelo Conselheiro de Estado Visconde de Cachoeira, e mandado observar provisoriamente nos Cursos Jurídicos de São Paulo e Olinda pelo Art. 10 desta Lei (10).

Embora demasiadamente longo o preâmbulo do projeto de Regulamento acima referido merece transcrição:

"Tendo-se decretado que houvesse, nesta Côrte, um Curso Juridico para nelle se ensinarem as doutrinas de jurisprudencia em geral, a fim de cultivar este ramo da instrução publica, e se formarem homens habeis para serem um dia sabios Magistrados, e peritos Advogados, de que tanto se carece; e outros que possam vir a ser dignos Deputados, e Senadores, e aptos para occuparem os lugares diplomaticos, e mais empregos do Estado, por se deverem comprehender nos estudos do referido Curso Juridico os principios elementares de direita natural, publico, das gentes, commercial, politico, e diplomatico, é de forçosa, e evidente necessidade, e utilidade formar o plano dos mencionados estıdos: regular a sua marcha, e methodo; declarar os annos do mesmo Curso; especificar os doutrinas que devem ensinar em cada um delles; dar as competentes instruções, porque se devam regser os Professores, e finalmente formalisar estatutos proprios, e adequados para bom regimen do mesmo Curso, e solido aproveitamento dos que se destinarem a esta carreira.

(10). - Art. 10 "Os Estatutos do Visconde da Cachoeira ficarão regulando por ora naquillo em que forem applicaveis, e se não oppuzerem à presente Lei. A Congregação dos Lentes formará quanto antes uns estatutos completos que serão submettidos à deliberação da Assembleia Geral": 
Sem estatutos, em que se exponham, e se acautelem todas estas circunstancias, não se poderá conseguir o fim util de tal estabelecimento. De que serviriam Bachareis formados, dizendo-se homens jurisconsultos na extensão da palavra, se o fossem só no nome? Não tendo conseguido boa, e pura cópia de doutrinas de são jurisprudencia em geral, por maneira que utilmente para si, e para o Estado podessem vir a desempenhar os empregos, para que são necessarios os conhecimentos desta sciencia, que sob os principios da moral publica, e particular, e de justiça universal, regula, e prescreve regras praticas para todas as acções da vida so. cial, haveria em grande abundancia homens habilitados $\operatorname{com}$ a carta somente, sem o serem pelo merecimento, que pretenderiam os empregos para os servirem mal, e com prejuizo publico. e particular, tornando-se uma classe improductiva com damno de outros misteres, a que se poderiam applicar com mais proveito da , sociedade, e verificar-se-hia deste modo o que receiava um sabio da França (11), da nimia facilidade, e gratuito estabelecimento de muitos lyceus naquelle paiz.

A falta de bons estatutos, e relaxada pratica dos que havia, produziu em Portugal pessimas consequencias. Houve demesiados Bachareis, que nada sabiam, e iam depois nos diversos empregos apreender rotinas cegas e uma jurisprudencia casuistica de arrestos, sem jamais possuirem os principios, e luzes dest $t$ sciencia. Foi então necessario reformar de todo a antiga Uriversidade de Coimbra; prescreverlhe estatutos novos, e luminosos, em que se regülaram com muito saber e erudição os estudos de ju-isprudencia, e se estabeleceu um plano dos estudos proprios desta sciencia, e as fórmas necessarias par ao seu ensino, progresso, e melhoramento:

Parecia portanto que á vista de taes estatutos, e das mais providencias, que depois se estabeleceram ácerca das facudices juridicas; e tambem do proveito que destas institui sultado, sahindo da Universidade grandes mestres, dignos e sabios magistrados, e habilissimos homens d'Estado, que aus nossos olhos tem illustrado e bem servido a patria, não era necessario outro novo regulamento, e bastava, ou para melhor dizer, sobrava que se ordenasse, que o novo Curso Juridico mandado estabelecer nesta Côrte, se dirigisse, e governasse pelos novos estatutos da Universidade de Coimbra com as alterações posteriores.

(11). - Peuchet, Annales de la legislation et de jurisprudence. Tomo II. 
Assim se persuadiram os autores do projecto de lei subre as Universidades, que se apresentou, e discutiu na extincta Assembléa Constitutinte e Legislativa, acrescentando que o Curso Ju ridico, que no referido projecto se mandava crear, logo, e ainda antes de estabelecidas as Universidades; se governasse por aquellas instituições, e novos estatutos, até que pelo andar do tempo, e experiencia, restringissem, ou ampliassem os Professores o que julgassem conveniente. Estas persuação fundava-se na facilidade e presteza, com que começava logo a pôr-se em pratica e provcitosa instiutição dos estudos juridicos.

Dado porém que se não possa negar, nem a sabedoria dos autores dos referidos estatutos, nem a demasiada cópia de doutrinas que elles contém, por maneira que é de admirar que houvesse em Portugal naquelle tempo de desgraça, e decadencia dos estudos em geral, e particularmente jurisprudencia, homens de genio tão transcendente que soubessem com tão apurada critica, e erudição proscrever o máo gosto dos estudos, substituir-lhes doutrina methodica, e luminosa, e crear uma Universidade, que igualou, e a muitos excedeu as mais celebres da Europa, todavia o seu nimio saber em jurisprudencia, e demasiada erudição de que sobrecarregaram os mesmos estatutos, e muita profusão de direito romano de que fizeram a principal sciencia juridica, a exemplo das Universidades da Allemanha; $o$ muito pouco que mandaram ensinar da jurisprudencia patria, amontoando só em um anno, e em uma só cadeira tudo que havia de theorico e pratico della; a pobreza do ensino de direito natural, publico, e das gentes (sem se lhe unir al parte diplomatica) e que devia ser ensinada em um só anno; a falta de direito maritimo, commercial, criminal, e de economia politica, que não foram comprehendidas nos estudos, que se deviam ensinar dentro do quinquennio, fazem ver que os referidos estatutos, taes como se acham escriptos, não podem quadrar ao fim proposto de se formarem por elles verdadeiros e habeis jurisconsultos.

Os mesmos autores dos referidos estatutos conheceram tanto que os estudos de direito diplomatico, e de economia politica deviam entrar na faculdade de jurisprudencia que declararan que os Professores dessem noticias delles aos seus discipulos quando conviesse; mas ne misto era estabelecer estudo regular, nem preceitos vagos podiam aproveitar.

A falta de estudos mais profundos de direito patrio foi supprida depois pelo Alvará de 16 de Janeiro de 1805, que deu nova fórma aos mèncionados estudos, e ao ensino da pratica do fôro es- 
tabelecida pelos autores dos Estatutos da Universidade de Coimbra para o $5^{\circ}$ anno juridico, ficando para o $3^{\circ}$, e $4^{\circ}$ anno $o$ ensino do direito patrio, com o que mais aproveitados sahem os estudantes-nestes tempos modernos, quando anteriormente vinham totalmente hospedes nos usos praticos, e sabendo mui pouco de direito patrio, e sua applicação, quando estes eram os estudos em que deveriam ser mui versados, pois se destinàvam a ser jurisconsultos nacionaes.

Se este deve ser considerado o fim primordial dos estudos jllridicos, salta aos olhos quão capital defeito era o pouco tempo que se empregava no estudo de direito pátrio, e sua applicação ao fôro. Posto que o estudo do direito romano seja uma parte importante da jurisprudencia civil, não só porque tem sido este o direito de quase todas as nações modernas, mas principalmente porque nelle se acha um grande fundo do direito da razão, pelo muito que os jurisconsultos romanos discorreram ajudados da phiThomasio Grocio, e Puffendorfio o que depois chamaram direito losophia moral; tanto assim que deste copioso manacial tiraram natural, e os celebres compiladores do Codigo de Napoleão. confessaram ingenuamente, que alli acharam um grande deposito a maior parte das regras que introduziram no mesmo codigo ;todavia é o direito romano subsidiario ou doutrinal, como em muitas partes dos mesmos estatutos confessaram os seus illustres autores, e não podia jamais ser ensinado com tanta profusão e extensão á cust ado direito patrio, por quanto ainda que em grande parte as nossas leis sejam extrahidas dos romanos, principalmente nos contractos, testamentos, servidões, etc.; ainda que seus compiladores eram mui versados no estudo do direito romano; com tudo é o direito patrio um corpo formado de instituiçóes proprias deduzidas do genio, e costumes nacionaes, e de muitas leis romanas já transvertidas ao nosso modo, e bastava por tanto, que depois do estudo das institutas se explicasse o direito patrio, e qu enos lugares de duvidas do direito romano trouxessem os Professores á lembrança o que se tivesse ensinado nas ditas institutas, expondo tudo o mais que ocorresse daquele direito, e indicando as leis romanas, onde existe a sua principal doutrina.

Além do que fica dito cumpre observar que a nimia erudição dos autores dos estatutos de Coimbra; a profusão com que a derramaram na sua obra, e muito e demasiado cuidado com que introduziram o estudo de antiguidades $e$ as amiudadas cautelas que ensinaram para a intelligencia dos textos, e que só deveriam servir para aclarar, e alcançar o sentido dos difficeis, fizeram que os 
estudantes sahissem da Universidade mal aproveitados na sciencia do direito patrio, e sobrecarregados de subtilezas, e antiguidades, que muito pouco uso prestaram na pratica dos empregos a que se distinaram. Os mesmos mestres e doutores, para se acreditarem de sabios perante seus companheiros e discipulos, faziam longos eprofundos estudos de direito romano e antiguidades, e seguindo nelles a escola Cujaciana, philosophavam muito theoricamente sobre os principios de direito, e por fugirem o rumo da de Bartholo, Alciato, e mais glosadores e causistas, ensinavam jurisprudencia mais polemica do que apropriada á pratica da sciencia de advogar, e de julgar. Não foi só no nimio estudo de direito romano a causa principal de se não formarem verdadeiros jurisconsultos; foi tambem, como já dissemos, a falta d eoutras partes necessarias da jurisprudencia, e que, fundadas na razão, preparam os animos dos que aprendem para conseguirem ao menos os principios geraes de tudo, que constitue a sciencia da jurisprudericia geral, e cujo conhecimento forma os homens para o sdiversos empregos da vida civil.

Se este é o fim a que nos destinamos na instituição deste Curso Juridico, se a experiencia já nos tem ensinado e convencido dos inconvenientes da pratica seguida; se conhecemos que a jurisprudencia é filha toda da sã moral; se sabemos que desde os primeiros elementos da ethica, e da moral nos vamos elevando cono por degráos ao cimo deste edificio; e se finalmente é da mais simples intuição que as sciencias todas se enlaçam, maiormente as moraes, que, de mistura com as instituições civis, são a base da jurisprudencia; por que não aproveitaremos estas lições do saber, e da experiencia, simples, e farto dos conhecimentos necessários e uteis, e que despido de rudiçõs sobjas, abranja o qu é mais philosophico e justo? Deve-se, portanto, sem perder de vista o que ha de' grande, e sabio em tão famigerados estatutos, cortar o que fôr desnecessario, instituir novas cadeiras para as materias de que nelles se não fez menção, as quaes são enlaçadas pelos mais fortes vinculos com a jurisprudencia em geral, e de nimia utilidade para o perfeito conhecimento della, e dirigimo-nos ao fim de crear jurisconsultos brazileiros, enriquecidos de doutrinas lumirosas, e ao mesmo tempo uteis, e que pelo menos obtenham nestc Curso bastantes, e solidos principios, que lhes sirvam de guias nos estudos maiores, e mais profundos, que depois fizerem; o que é o masi que se póde esperar que obtenham estudantes re um curso academico.

Os autores dos mesmos estatutos, no Curso Juridico que regularam, comprehenderam o direito canonico, e por maneira es- 
tabeleceram a fórma de estudos de ambas as faculdades juridicas, que os primeiros dous annos são inteiramente communs acs estudantes dellas, ajuntando-se depois nos annos, e aulas, em que se ensinava o direito patrio, e pratica do fôro. Considerada a necessidade de haver um curso de direito canonico, muito bem se houveram prescrevendo aos alumnos que se destinavam á faculdade de canones o conhecimento das institutas do direito civil, e os das instituições de direito publico, ecclesiastico de direito caronico aos alumnos de direito civil, attenta a relação, e affinidade que ha em geral entre estes estudos. Contudo não entrará o cnsino da faculdade de canones no Curso Juridico, que se vai instituir. Esta sciencia, toda composta das leis ecclesiasticas, bem como a theologia, deve reservar-se para os claustros e seminarios episcopaes, como já se declarou pelo Alvará de 10 de maio de $1805 \S 6^{\circ}$, e onde é mais proprio ensinarem-se doutrinas semelhantes, que pertencem aos ecclesiasticos, que se destinam aos diversos empregos da igrcja, e não a cidadãos seculares dispostos para os empregos civis.

Como porém convenha a todo o jurisconsulto brazileiro saber os principios elementares de direito publico, ecclesistico, universal, e proprio da sua nação, porque em muitas cousas, que dizem respeito aos direitos do chefe do governo sobre as cousas sagradas e ecclesisticas, cumpre saber os principios, e razões em que elles se estribam, convirá que se ensinem os principios e!cmentares de direito publico, ecclesistico, universal, e brazileiro em uma cadeira, cujo Professor com luminosa e apurada critica e discernimento assignale as extremas dos poderes civil e ecclesiastico.

Por estes ponderosos motivos, e dest'arte s eorganizam os estatutos, que hão de reger o Curso Juridico, que vai a ensinar-se nesta Côrte, o qual abrangerá portanto os conhecimentos que formam o todo da faculdade da jurisprudencia civil".

Em 15 de outubro de 1827, é aprovada uma das mais importantes Leis da década, que se atendida, não seríamos de então até nossos dias, um país de analfabetos. Estabelecia o Art. 1. ${ }^{\circ}$ :

"Em todas as cidades, villas e logares mais populosos, haverão as escolas de primeiras letras que forem necessárias.

Esta, como tantas outras, ficou apenas na publicação...

José Bernardino B. Pereira, assina a Decisão n. ${ }^{\circ} 82$ - Fazenda - Em 2-7-1828, estabelecendo que 
"O Thezoureiro Geral dos ordenados, juros e pensões ticue na intelligencia de que pagamento algum se deve fazer aos Professores publicos, sem que os mesmos Professores apresentem attstados authenticos do seu effectivo exercicio".

A Decisão n. ${ }^{\circ} 100$ - Império - Em 26 de julho de 1828. resolve as dúvidas propostas pelo Lente da 2. a cadeira do $2 .^{\circ}$ ano do Curso Jurídico de São Paulo sobre as matérias que deve ensinar, e o compêndio por onde há de lecionar.

A Decisão seguinte, n. ${ }^{\circ} 101$ - Império - Em 27 de julho de 1828 , determina que não sejam cursadas ao mesmo tempo as aulas de retórica e filosofia, e aprova a nomeação de um estrangeiro para ensinar gratuitamente geometria no Curso Jurídico de São Paulo.

As duas últimas Decisões são exemplos de quanto era minuciosa a regulamentação dos estudos. Os detalhes, as mínimas dúvidas eram resolvidas através de Leis:

O Ministro e Secretário de Estado dos Negócios do Império, José Clemente Pereira, é autorizado por Sua Majestade Imperial a expedir os despachos necessários para aposentar,

“. . . com ordenado inteiro, a João Batista Soares Meirelles, professor publico, proprietario de uma das cadeiras de Grammatica Latina" (12).

"Tendo o Dr. Joaquim Candido Soares de Meirelles exposto a utilidade de abrir um Curso de Medicina Pratica par aos alumnos da Academia Medico-Cirurgica desta Côrte, declarando ser compativel aquelle trabalho com o da visita diaria do hospital da Sta. Casa de Misericordia, de que é medico . .."

A Secretaria de Estado dos Negócios do Império, n. ${ }^{\circ}$ 145, em 4-10-18.28 concede licença para a abertura de um Curso de Medicina Prática na Corte.

\section{Por meio de subscrição publica e “. . . com auxilio de alguns soldados . . ."}

foi construida uma casa para o estabelecimento do ensino mútuo, na cidade de Natal, que através da Decisão n. ${ }^{\circ} 146$ - Império. Em 410-1828 manda incorporar aos próprios nacionais o referido edifício.

(12). - Decreto de 25/9/1828. 
Os Lentes que interinamente regerem cadeiras, na ausência dos proprietários ocupados na Câmara dos Deputados, devem perceber a quinta parte do ordenado destes, é o que estabelece a Decisão n. ${ }^{\circ}$ 184 - Fazenda. Em 28-11-1828.

A Decisão Império n. ${ }^{\circ} 8$, de 10-1-1829, pede uma relação de todos os colégios e casas de educação existentes nas províncias, declarando:

": . . 19 os nomes dos Directores, seu estado, idade e naturalidade, $2^{\circ}$ se têm licença para ensinar, quaes os estudos qque os regem, e se estes sã̃o aprovados, em por quem, $3^{\circ}$ que fundos possuem, ou de que meios dispõem para às respectivas desrezas. Igualmente determina o mesmo Senhor que sendo nacionaes os Directores, e regendo sem licença ou confirmação dos estatutos, sejam obrigados a pedil-as, dentro de 3 0dias, ... Sendo porem estrangeiros, devem requerer tanto a licença como a confirnıação diretamente ao Governo . . . E como a instrução da mocidade é um dos primeiros objectos da paternal solicitude de Sua M.agestade, Ha outrossim por bem que V. Ex, inspecione os sobredictos estabelecimentos, mandando visitadores quando the parecer acertado e dando parte todos os semestres do numero, idade e naturalidade dos alumnos, seus estudos e progressos, e cuidando escrupulosamente que haja todo o desvelo na educação religiosa e regularidade de costumes, como bases principaes da boa ordem na sociedade".

Com a data de 7 de abril de 1829 , a Decisão n. ${ }^{\circ} 65$ - Império, resolve dúvidas sobre exames dos estudos preparatórios nos Cursos Jurídicos:

"Sendo presente a Sua Magestade o Imperador o officio de V. S. de $1^{\circ}$ de março p.p a respeito de alguns estudantes que, tendo sido reprovados nos exames preparatorios, allegam todavia motivos, pelos quaes se julgam nas circunstancias de fazerem segunda vez os mesmos exames e referindo-se V. S. o que sobre isto aconteceu com o estudante Manuel Francisco Lopes, que, reprovado no primeiro exame de francez, não foi admitido a segunda pelo Lente José Maria de Avelar Brotero, em oposição ao despacho de V. S. que se queixa deste procedimento: Ordena o mesmo Augusto Senhor se responda a V. S. que os estudantes, que forem reprovados não podem entrar em segundos exames, sem que tenha mediado tempo suficiente para nova applicação, $\approx$ jun- 
tarem para aquelle fim as competentes attestações dos respectivos professores ..."

A Decisão n. ${ }^{\circ} 99$ - Império. Em 30 de maio de 1929, dá regulamento para a Biblioteca Pública da cidade da Bahia. Interessante o Capítulo I que sob a denominaçằo - Do Serviço Público estabelece:

"A Bibliotheca estará todos os dias aberta, desde as 9 horas da manhã até a 1 da tarde, à excepção dos domingos, dias santos e de grande gala. Serão admittidas todas as pessoas que se apresentarem decentemente vestidas. Franquear-se-ha indistinctamente qualquer livro qu ese pedir, e papel, pennas e tinta para se fazerem apontamentos. A ninguem se emprestará livro algurn para fora da Bibliotheca, sem licenç̧a do Presidente da Provincia por escripto, para justificar o Bibliotecario, e autoriza-lo para a reclamação. Não poderão as pessoas admittidas tirar das estantes os livros, nem restituil-os a ellas. Em ambos os casos se devem dirigir a quem toca esse serviço. Sendo indispensavel que se conserve a casa em socego e silencio, a nenhuma pessoa, sej adas admittidas, seja das empregadas, será permittido passear nella, nem travar convervações, ou disputas, ainda que sejam scientificas".

O Decreto de 19 de novembro de 1829 , cria uma comissão encarregada de organizar um projeto de regulamento para escolas de primeiras letras, e justifica:

"Sendo indispensável regular convenientemente a instrucção da mocidade nas Escolas de primeiras letras, tanto pelo syctema Lancaster, como pelo antigo: Hei por bem crear uma Conınição composta dos professores Antonio Maria Barker, Felizardo Joaquim da Silva Moraes, Francisco Joaquim Nogueira Neves, João José Sarmento e Marcelino Pinto Ribeira Duarte; a qual teri por primeiro objecto em seus trabalhos organizar um projecto de regulamento para as referidas escolas, e ordenar compendios, pelos quaes methodicamente se ensinem as materias declaradas no artigo sexto da Lei de quinze de outubro de mil oitocentos e vinte e sete... (13).

(13). - "Os professores ensinarão a ler, escrever, as quatro operaçñes de arithmetica, pratica de quadrados, decimaes e proporções, as noções mais geraes de geometria pratica, a grammatica da lingua nacional, e os princinios de moral christã e da doutrina da religião catholica e apostolica romana, proporcionados à comprehensão dos meninos; preferindo para as leituras a Constituição do Imperio e a Historia do Brazil . . ." 
E' criada na Corte uma Comissão de Estatística Geográfica e Natural, Política e Civil, pelo Decreto de 25 de novembro de 1829, pelas razões seguintes:

"Sendo reconhecida a necessidade de organizar a Estatística deste Imperio pelas vantagens que do seu exacto conhecimento devem resultar para os trabalhos da Assembléa Geral Legislativa, e para os actos do Poder Executivo: Hei por bem crear nesta Côrte uma Commissão de Estatistica Geographica e Natural, Politica e civil ..."

Este ligeiro apanhado não é senão uma pequena parcela de um trabalho mais amplo que vimos elaborando a respeito da Educação Brasileira na Legislação.

Porém, quisemos aproveitar esta Reunião para apresentarmos, ainda que sob a forma de simples enumeração os primeiros elementos que temos colhido a respeito. Podemos assim estabelecer o cuidado que desde logo procurou o Governo PortuguGs resolver os problemas educacionais .

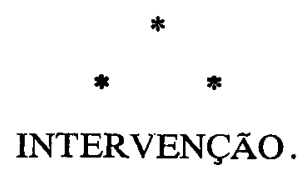

Do Prof. Earle D. Macarthy Moreira (IFCH-UFRGS).

Declara que, como a Autora deu ênfase especial ao problema das verbas para explicar o fracasso dos projetos, pergunta: as dificuldades de comunicação não teriam influido nesse fracasso? As distâncias que estão explicitamente mencionadas na documentação apresentada podem dar uma resposta. As discrepâncias verificadas entre o ideal de uma política educacional (pareceu-lhe notável e clarividente para a época) e as realidade tangíveis e palpáveis levam, sem dúvida, a conclusões bem mais complexas (*).

(*). - A Autora deixou de enviar, por escrito, à Mesa, a resposta dada à interpelação feita em plenário (Nota da Redação). 